\title{
Decision-Making Models for Healthcare Supply Chain Disruptions: Review and Insights for Post-pandemic Era
}

\author{
Aarti Singh $^{1}\left(\mathbb{D} \cdot\right.$ Ratri Parida $^{2,3}$ (1) \\ Received: 28 September 2021 / Accepted: 18 December 2021 / Published online: 17 January 2022 \\ (c) The Author(s) under exclusive licence to Global Institute of Flexible Systems Management 2022
}

\begin{abstract}
The black swan event caused by the novel coronavirus (COVID-19) has majorly exposed the vulnerabilities of the supply chain of many of the firms. However, healthcare sector is one of the significant areas which majorly got disrupted during this pandemic event. The majority of the studies focus on the reviews on supply chain disruption modelling to analyse the risk and their effect on supply chains. This study provides a systemic literature review of various supply chain disruption models in the healthcare sector, analyses them based on different parameters identified from the literature. Some of our key findings include (1) analysis of quantitative and analytical modelling approaches used for dealing with disruption in healthcare sector; (2) managerial implications that derive potential future research avenues and insights for practitioners in the domain of healthcare supply chain disruption in post-pandemic era to improve international competitiveness and operational excellence.
\end{abstract}

Keywords Healthcare sector · Supply chain disruption · COVID-19 · Risk management · Quantitative modelling · Analytical modelling $\cdot$ Supply chain competitiveness

\section{Introduction}

Supply chain disruption are viewed as a mix of unexpected setting of occasions and the subsequent results which risk the progression of material and ordinary business exercises significantly (Wagner \& Bode, 2006). There are several risks associated with Supply Chain. They are classified into operational and disruption risk (Tang, 2006; Xu et al., 2020). Operational risks refer to day-to-day disruptions in Supply Chain operations, such as fluctuation time and lead time, whereas Disruption Risks belong to low-frequency highimpact events (Ivanov et al., 2017). Disruption risks can be categorized into natural (earthquake, flood, fire, COVID19 , etc.) and man-made (terrorist, accident, the bankruptcy

Ratri Parida

ratriparida@gmail.com

Aarti Singh

phd19aartis@iimsambalpur.ac.in

1 Indian Institute of Management Sambalpur, Sambalpur, Odisha, India

2 Department of Operations Management, IMT Ghaziabad, Ghaziabad, India

3 Guildhall School of Business and Law, London Metropolitan University, London, UK of supplier, etc.) (Fahimnia et al., 2015). These risks have an immediate impact on the Supply Chain network since links of Supply Chain are temporarily disturbed and unavailable. There are several disruption events that have been well documented. Some of them are the COVID-19, 09/11 terrorist attack, Hurricane Mitch, Earthquake in Taiwan (1999), Eruption of Volcano in Iceland (2010), Flood of Thailand (2011), Tsunami in Japan (2011), Explosion at BASF factory in Germany (2016), etc. (Dolgui \& Ivanov, 2021; Fahimnia et al., 2015). In 2015, a series of the explosion at a container warehouse for toxic chemicals at Tianjin Port caused significant environmental changes like Water cyanide level exceeded from accepted limit, destruction of 8000 newly produced car and shutdown of 2 manufacturing plants of Toyota (Bugert \& Lasch, 2018). According to report by EY 2020, almost all the industries like Automobile, Electronics Manufacturing, Food Processing, Gems and Jewelry, IT, Leather, Medical devices and Equipment, Metals, Minerals, Pharmaceuticals, Plastics and Packaging, Real Estate and Construction, Retail and e-commerce, Textile and Apparel and, Tourism and Hospitality are affected by COVID-19 pandemic as well (EY 2020; Deshmukh \& Haleem, 2020). Furthermore, black swan events like Influenza pandemic, and COVID-19 pandemic has badly affected the Healthcare 
Supply Chain (Francis, 2020; Govindan et al., 2020; Hovav \& Tsadikovich, 2015).

Disruption has played a crucial role in Healthcare Supply Chain (HSC). Healthcare supply chain management is defined as the regulation of the flow of medical and essential goods and services from manufacturer to patient. In Healthcare, supply chain management is typically a very complex and fragmented process (Saviano et al., 2014). Regardless of the severity of the disruption events, organizations need to take unprecedented measures for preventing or mitigating the risk caused by disruption events.

Although Supply Chain Disruption Modelling is widely studied in the last decade, its application in the Healthcare sector is prolonged because disruptions are not so frequent. Substantial amount of literature is available in Supply Chain disruption domain. However, there is scarcity of studies that focuses on the quantitative modelling approaches used for dealing with disruption in Healthcare Industry. To the best knowledge of author's this, a systemic literature review in the arena of quantitative modelling used in healthcare industry has not been conducted previously. This work bridges the gap by systematically analysing the all the quantitative models used in healthcare sector Supply chain disruption.

Specifically, we have defined three research questions to specify the goals of this literature review:

(a) Which modelling techniques are used for supply chain disruption modelling in healthcare?

(b) How well the identified models and modelling techniques take the identified risk-specific modelling characteristic into account?

(c) What are the open questions and future research directions in the area of supply chain disruption modelling in healthcare sector post-pandemic?

The organization of this paper is as follows. The next section describes the paper's research methodology followed by the significant problems associated with healthcare supply chain disruption, then the evaluation criteria with respect to the existing modelling approaches for healthcare supply chain disruption are explained. After interpreting the results of the evaluation, the last section summarizes the findings from the reviewed literature and offers a general look at future research in the field of the study.

\section{Research Methodology}

The literature regarding supply chain disruption modelling in healthcare sector is limited. To attain the objective of this paper, we have reviewed the papers related to supply chain disruption modelling in the Healthcare Sector. In the first stage, we performed the search to identify the related papers from various databases like Scopus, Google Scholar, JSTOR archive, ProQuest, INFORMS Pubs Online using keywords, such as 'healthcare', 'hospital', 'medicine', 'pharmaceutical', 'blood', 'medical' in combination with 'supply chain disruption' and 'modelling'. In the first phase, 60 journal articles were obtained. Out of those 60 research articles, 55 were taken into consideration after the removal of duplicated article. In the next step, we consider only those papers which met our research criteria i.e., we have excluded the unpublished articles, book chapters and thesis. In the same line, we have also excluded the articles not present in English Language and considered only 33 articles for final review purpose. In the last stage, we analysed the main findings from the analysis of the papers. This study presents a critical analysis on relevant and existing literature on Healthcare Supply Chain Disruption Modelling for a way forward to cope up with the risks post-pandemic as is presented in Fig. 1.

\section{Problems Associated with the Healthcare Supply Chain}

HSCs are different from the standard supply chain due to its complex nature, the presence of high-value medical materials, and, most importantly, the fact that they deal with human lives. According to Kitsiou et al. (2007), a typical HSC consists of focal entities (hospitals), backward entities (Manufactures), and forward entities (private and public payers) as presented in Fig. 2. Mathew et al. (2013) defined another version of HSC. According to him, the chain starts with the flow of different products, and it involves several stakeholders. In addition to this, HSC also requires the participation of government institutions, regulatory agencies, and insurance companies (System et al., 2005). Rivard-Royer et al., (2002) identified two chains that are mainly associated with HSC: the first one is related to storage within the hospital, etc., whereas the second one is related to distributors and manufacturers, etc.

There are several problems associated with HSC like variability and unpredictability of patient profile and high demand of care, integrated planning systems between patient flows and different health service organization, reduction of waste, unnecessary cost elimination while improving the quality (Bourlakis et al., 2011; de Vries \& Huijsman, 2011; Wieser, 2011; Battini et al., 2014). Usually, HSCs maintain high levels of stock to provide $100 \%$ service level. The drug demand is highly unpredictable. Some drugs have very less shelf-life; some are used in more amount some used in less amount. With rising in a turbulent environment, Hospital organizations need to be flexible so that they can manage 
Fig. 1 Step-wise research methodology for SLR

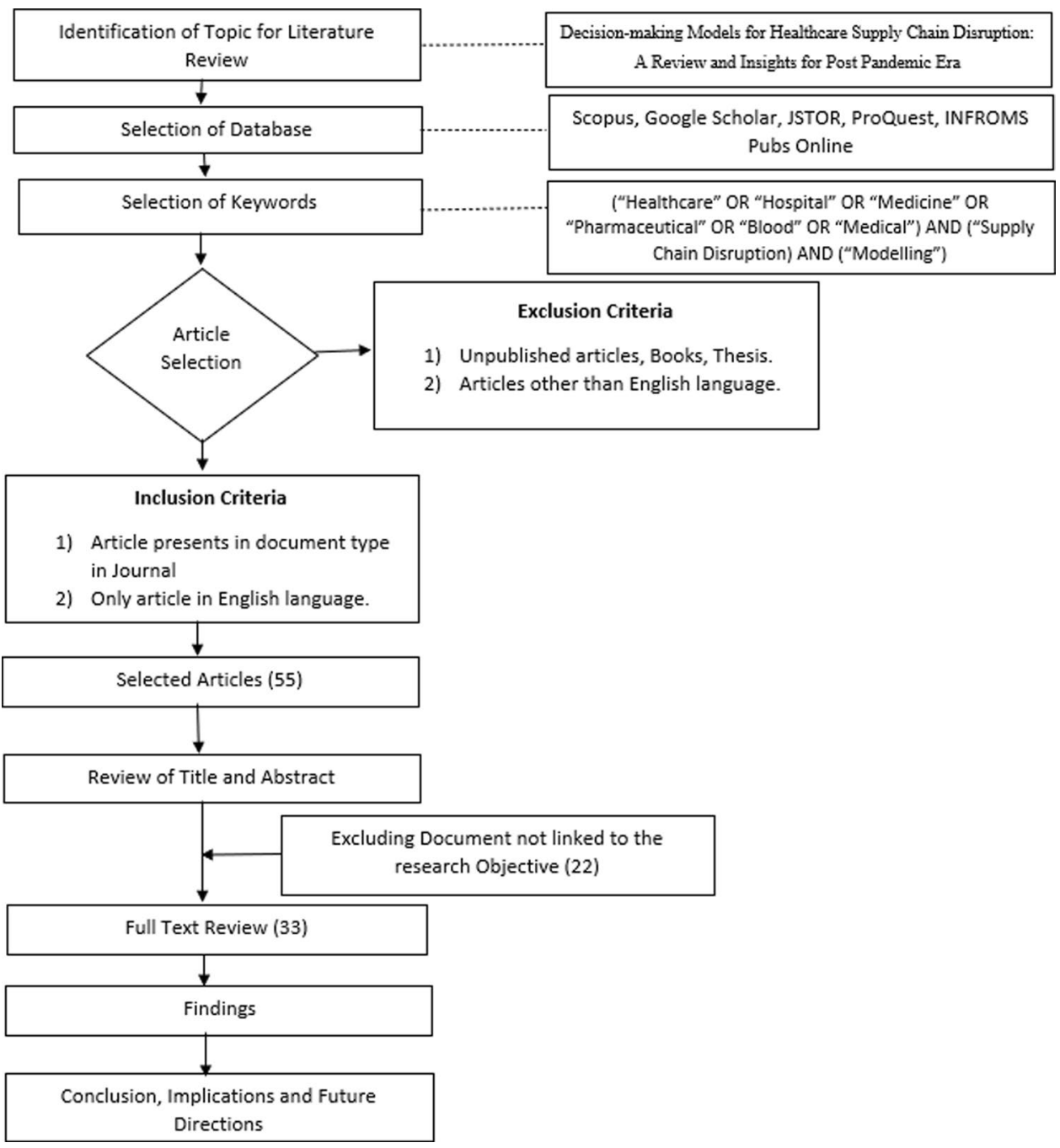

Fig. 2 Typical healthcare supply chain

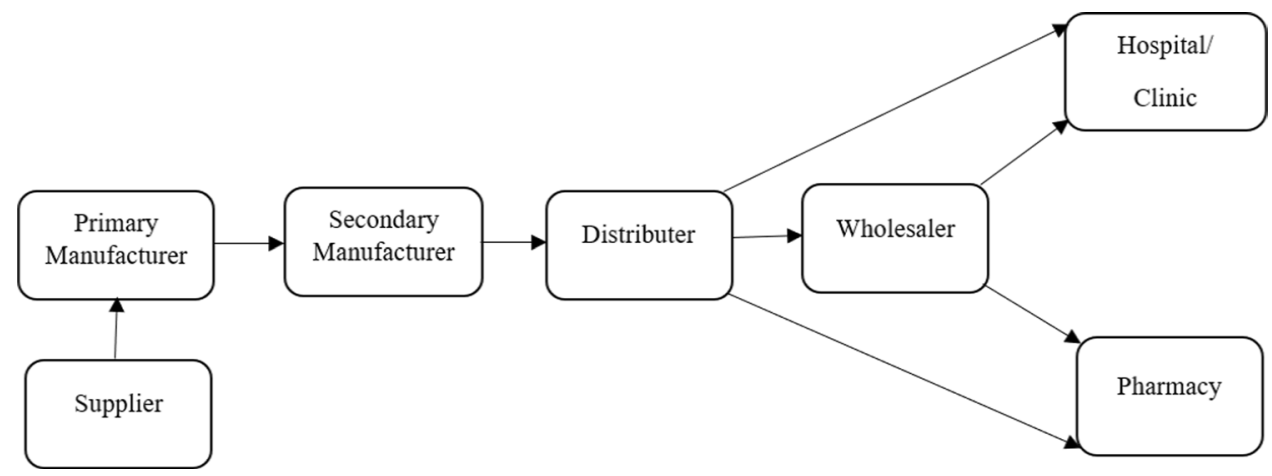

uncertainties and helps in risk mitigation strategies (Bag et al., 2018; Sushil, 2017).

Other specific issues are cited as follows:

- The health care supply chain is very complex in comparison to the standard supply chain because of the presence of essential and nonessential medical items. In addition to this, human lives are associated with HSCM (Aldrighetti et al., 2019).

- Harmful waste is associated with HSC. There is a need for a reduction in waste. Healthcare systems have a pressure to reduce the cost for the elimination of waste mate- 
rial without hampering the quality of care provided to patients (Battini et al., 2013).

- HSC needs to maintain high levels of stock to provide a $100 \%$ service level. This leads to an increase in cost (Neve \& Schmidt, 2021). During the COVID-19 outbreak, the demand for drugs became highly unpredictable, which further leads hospitals to overstock and sometimes understock.

- Requirements of patients and their expectations are changing with time leads to difficulty in managing the HSC (Kumar et al., 2018).

- HSC needs to be flexible so that it can quickly adapt to external changes (Dubey et al., 2019).

- HSC needs to increase the responsiveness and to mitigate the risk (Dubey et al., 2019).

Furthermore, healthcare sector is continuously facing several operational challenges during and beyond COVID19 pandemic in several ways like low bed capacity, lack of medical resources, vaccines, PPE kits and equipment", staff shortage in healthcare industry", mismatch between demand and supply of essential, and uncertainty in demand with each upcoming wave, etc. (Burgess \& Radnor, 2013; Leung et al., 2020; Leite et al., 2020). Therefore, proper contingency plan need to be in place for mitigation of such risks.

\section{Evaluation Criteria for Healthcare Supply Chain Disruption Models}

To the best of our knowledge, this paper is the first one where we will discuss modelling approaches related to supply chain disruption in Healthcare Sector. Table 1 shows all the criteria with their measurable indicators.

Understanding of propagation helps to form the mitigation strategies and reduction of risks in the supply chain.

Table 1 Derived evaluation criteria for healthcare supply chain disruption modelling

\begin{tabular}{lc}
\hline Evaluation criteria & Indicators \\
\hline Number of considered risks & $\begin{array}{c}\text { (One, two, } \\
\text { three or } \\
\text { more than } \\
\text { three })\end{array}$ \\
& Yes/no \\
Consideration of risk propagation & Short term \\
Duration of risk & (ST)/long \\
& term (LT) \\
Risk identification & Yes/no \\
Risk assessment & Yes/no \\
Risk mitigation & Yes/no \\
Risk optimization & Yes/no \\
\hline
\end{tabular}

According to Qazi et al., (2015), risk propagation is a trendy topic for future research. In our review, if propagation is considered in the modelling approach, then it satisfies our criteria. We have also checked the duration of risk in modelling approaches that either the effect on supply Chain is for Short term or Long term. Supply chain models have a specific objective of reducing the vulnerability of the supply chain or increases the resilience of supply chain. Appropriate strategies can optimize these things if the future risk situation of the supply chain can be predicted well. In our review, if any mitigation strategy is involved in the modelling approach, then it satisfies our criteria. According to Chopra and Sodhi (2004), there are no simple strategies for prevention or completely reduce the impact of disruption. Mitigation Strategies are defined as actions taken by a firm to lessen the risk of disruption. Mitigation strategies are categorized into 4 different parts: elimination of risk, reduce the frequency and consequence of risk, acceptance of risk, and transfer the risk by sharing (Zsidisin \& Richie, 2009).

Our work is focused on risk-related criteria and leaves out other general points like the flexibility of modelling approaches and the complexity of modelling approaches.

\section{Evaluation of Identified Healthcare Supply Chain Disruption Modelling}

The identified literature can be broadly classified according to the use of modelling techniques since different modelling approaches have their characteristic features with some pros and cons.

\section{Optimization Methods}

Optimization is a relatively new approach to optimization of uncertainty affected issues. In has already been proven that this is one of the most potent techniques for tackling real-life problems that mostly deals with uncertain events (Aharaon et al., 2009). This technique can be used with both a single objective optimization problem as well as a multiobjective optimization problem. It provides a solution that has an acceptable performance under most of the uncertain events. Peng et al. (2011), Pishvaee et al. (2011) have used robust optimization in a single objective context. In the biobjective context, robust optimization is used by Fahimnia et al. (2017), Diabat et al. (2019).

Mete and Zabinsky (2010) presents a Stochastic optimization approach for storage and distribution of medical supplies in disaster condition. To prepare against disaster, the Stochastic programming model has been developed for the selection of storing locations of medical supplies and inventory levels for each medical supply. Jabbarzadeh et al. (2014) develop a dynamic, Robust stochastic optimization 
model for designing the supply of blood during and after the disaster. This model can assist in blood facility location and allocation decisions for multiple post-disaster periods. Hamdan and Diabat (2020) developed a multi-stage optimization model for the blood supply chain. In this model, robust optimization two-stage stochastic optimization was used for the mitigation of the effect of disasters, optimization of total costs and consideration of delivery time of blood to the hospitals.

\section{Game Theory}

Game theory helps to decide the best possible option in the conflicting decision. It simply provides the general rule of logic but does not give the winning strategy. In real-life scenarios, there is much uncertainty that has not been considered in the Game theory approach. Delaurentis et al. (2008) develop a Game theory approach for solving the problem of medical stockpiling in preparation for a flu pandemic. This paper aims to develop an analytical approach for determining the appropriate stockpile levels of critical medical items (excluding vaccines) under various flu pandemic scenarios. This paper focuses on group decision making for a community of hospitals. It has been found out in the study that the hospital's decision on how much stockpile of one item needed depends not only on uncertainties but also on its mutual aid relationship with other hospitals. Adida et al. (2011) use the Game Theory approach for joint inventory stockpiling of medical supplies for a certain group of hospitals before the disaster. During the disaster, demand is uncertain. That is why there is a need for stockpiling of medical supplies. The objective of this paper is to estimate the amount of stockpile in a decentralized setting by minimizing the total cost of Stockpiling. The model is also compared with the centralized setting. Mamani et al., (2013) proposes a game theory model to contract the coordination mechanism for influenza vaccine.

\section{Queuing Theory Model}

Queuing theory is used for modelling of those processes which involve problems related to waiting lines. Basically, it is used for the mathematical study of formation, function, and congestion of waiting for lines (McManus et al., 2004). Many health researchers and health care managers have been using queuing theory since 1950 to describe and analyse the hospital system (Baily, 1952; Green \& Nguyen, 2006; Worthington, 2009). Over the years, a number of theoretical, analytical queue models were developed for the analysis and enhancement of the performance of hospitals and their subsystems. The performance metrics usually calculated using calculations formulas developed in queueing theory include time-waiting for measures, congestion measures, idle time measures, and the use of the server. Hui. (2010) constructed a model for analysing and interpreting time-optimal control of the distribution of antibiotics in case of the bioterrorist attack in a metropolitan queuing network which has been considered in this paper. Mainly, antibiotic distribution is considered in various stages of the disease.

\section{Simulation}

A simulation of the supply chain shows the behaviour over time of the logistics network. A model shows the logical network of the supply chain, and it is then executed over time to dynamic the simulation. Lee (2008) develops a simulation model for evaluating the effectiveness of alternative dispersiveness plans for emergency medical supplies (vaccine and antibiotics) in the event of bioterrorism in US. In this paper, the author assesses and analyses logistics and supply chain plans for distributing vaccines in smallpox attack. Azghandi et al. (2018) use a mathematical simulation model to examine the effect product recalls considering different disruption scenarios like propagation in time and space, interactions of decision-makers on drug shortages to ascertain how these shortages can be mitigated by changing decision policies related to inventory. Aldrighetti et al. (2019) have used a simulation approach to analyse the effect of disruption and mitigation strategies. Haghjoo et al. (2020) develop a Dynamic robust allocation model for designing a blood supply chain under facility disruption risks and uncertainty in a disaster situation. It has been considered that the effect of disruption in facilities depends on the initial investment level, which is affected by the allocation budget. Paul et al. (2020) proposed a Bayesian Network Model for tranportation risk associated with pharmaceutical supply chain disruption in Bangladesh context.

Discrete event simulation (DES) is a way to simulate the dynamic behaviour and performance of a real-life scenario. DES concept models have modelled a wide range of supply chain planning issues, including supply chain design, inventory planning, production scheduling, and supplier selection (Tako \& Robinson, 2012). Simulation only allows "what if" analysis whereas enables decision-makers to test and better understand possible ways to meet a new strategy.

Elleuch et al. (2014) describe the supply chain risk approach to assist decision-makers to risk identification, assessment and management. The approach combines for several techniques like Failure mode, effects, and critical analysis (FMECA) to identify the risk and its current location, Design of experiment (DOE) to design risk mitigation and action scenarios, Discrete event simulation to assess risk mitigation scenarios and Analytic hierarchy process (AHP) method to evaluate the risk management scenarios. 


\section{Mathematical Modelling}

Compartmental models are used to perform the mathematical Modelling of infectious diseases. In this method, the population is divided into compartments with different labels like susceptible, infectious, and recovered. The origin of this model is from the work of Kermack et al. (1927). Arinaminpathy and Mclean (2008) use Mathematical Modelling (differential modelling and compartmental Modelling) for stockpiling of antiviral drug Tamiflu. Liu (2007) develops a mathematical model that can be used for derivate ng necessary stockpiling level for the vaccine to meet the urgent need in the natural outbreak of epidemic disease. It has been considered in the paper that there is a shortage of vaccines due to high demand, but production is normal. The goal is to minimize the shortage, given a fixed total cost (both waste and inventory holding cost). Firstly, an oversimplified model has been developed. In the next step, a more realistic model has been developed. Kamp et al. (2010) use mathematical models and computer simulations to find the availability of blood products during Influenza epidemic. The spread of Influenza diseased is modelled by the compartmental susceptible-infected-recovered model (SIR model). Sha and Huang (2012) propose a multi-period location model for scheduling of blood in an eemergencyncy after an earthquake in Beijing. Govindan et al. (2020) used the Fuzzy interface system in healthcare system for reducing stress in the community, breaking the propagation of COVID-19 and mitigating the epidemic outbreak for healthcare supply chain disruption. Chick et al., (2008) design a cost sharing contract for influenza vaccine supply chain.

\section{Mixed Integer Linear Programming}

Mixed-integer linear programming is developed for the design of the high dimensional and nonlinear system. It is used for system analysis and optimization as it presents a flexible and robust method for solving a large and complex problem. Shishebori and Yousefi Babadi (2015) use a mixed-integer linear programming model for designing a robust and reliable medical service (MS) centre location network design. It considers uncertain parameters, system disruptions, and investment budget into account. The model is based on a robust optimization approach. Hasani and Khosrojerdi (2016) created mixed integer-linear model for designing a robust global supply chain network for a medical device manufacturer under uncertainty to maximize the total after-tax profit. Liu and Zhang (2016) developed the FPEA model for the study of the dynamic allocation of medical resources in the control of an epidemic diffusion. This model is used for logistics planning for satisfying forecasted demand and minimizes the total cost. Lücker and Seifert
(2017) use it to analyse optimal risk mitigation strategies for a single firm that is affected by supply chain disruption risk. The paper focuses on Risk mitigation inventory (RMI) and process flexibility decisions for a pharmaceutical firm. Timajchi et al. (2019) proposed a bi-objective mixed integer mathematical programming for the inventory routing problem of hazardous and deteriorating pharmaceutical items in a healthcare network.

\section{System Approach}

System dynamics is a very abstract modelling method. It ignores the fine details of the system, such as individual properties of individuals, products, or events and generates a general representation of a complex system. Brailsford et al. (2004) used a system dynamics approach for reviewing emergency and on-demand healthcare in Nottingham, England. Parvin et al. (2018) develop a solution methodology that integrates strategic-level and tactical level models for managing the distribution of malaria medications, such as Artemisinin combination therapies in three-tier centralized health system. A two-stage stochastic programming model was constructed at a strategic level for addressing the demand uncertainty problem. For the tactical level, the Markov decision approach was used for determining the optimal periodic transhipment policies.

\section{Agent-Based Model Approaches}

Agent-based Modelling is a modelling and simulation method in which multi-agent systems represent social, economic, and ecological systems, etc. (Salamon, 2011). An agent is an independent, self-oriented and human agency that can act independently from other agents. It interacts with and reacts to other agents and their environment by having a simple collection of rules of it and then or by integrating complex techniques of artificial intelligence into its behaviour (Taylor, 2014). Wang et al. (2012) describe agentbased simulation for an emergency response to a mass causality incident in an urban area. The model is developed with the help of geographic information system (GIS) data and resource Information which facilitates building of an model for area where both GIS and resource data are available. In last, simulation models are used for evaluation of provided options which may help policy makers.

\section{Hybrid Model}

Anagnostou et al. (2013) developed an integrated model of Discrete event simulation (DES) and agent-based simulation (ABS) for emergency medical services. The DES was used to model the workflow of the EMS for the identification 
of system bottlenecks. Whereas ABS integrated geographic information system for modelling ambulance movements and their interaction with the operation centre. Fakhimi et al. (2015) presented an integrated model of DES and ABS for the analysis of sustainable planning strategies for EMS. ABS paradigm was used for Modelling of ambulance services (emergency call centre, vehicles and crews) while considering environmental, social and financial factors for sustainability modelling. At the same time, DES paradigm was used for the analysis of resulting data of ABS paradigm. Shamsi et al. (2018) constructed a specific option contract for proactively provisioning required vaccine from two suppliers (main supplier and a backup supplier). This model goal is to minimize procurement and social cost. A hybrid solution was proposed to find the optimal solution in which optimal control, Stackelberg game model and nonlinear programming approach are included. It has found from the study that policy-making decisions influenced by the season in which disease occurs. The transmission rate of disease, natural recovery rate and natural deaths are variables that plays major role in decision-making process of epidemic diseases. Fahimnia et al. (2017) use a Stochastic bi-objective model for efficient and effective blood supplies in disasters. The blood supply network consists of Blood donors, mobile blood facilities, local and regional blood centres, and demand points.

Table 2 briefly describes all the modelling approaches used in supply chain disruption in healthcare industry.

\section{Results and Discussion}

Currently the world is fighting with COVID-19 pandemic, which affects almost all the sectors whether it is Hospitality, Aviation, Tourism, Manufacturing, E-commerce, Retailers (Business News, 2021). But it has severely caused disruption in Healthcare Sector in terms of demand uncertainty for PPE kits, Vaccines, Medical devices, and Pharmaceuticals (DeSalvo et al., 2019). There have been several quantitative modelling approaches used in different disruption events and during pandemics like Robust Optimization, Simulation, Mathematical programming, Game Theory and Queuing Theory. Only Govindan et al., (2020) has proposed fuzzy modelling in case of COVID-19 but still there has been a lot of scope for applying mathematical programming, game theory, optimization approaches, and simulation for risk identification, assessment and risk mitigation caused by COVID19 pandemic (Gupta \& Soni, 2021). As has been highlighted in Table 2, very few of the articles have considered multiple risks in their methodology. Moreover, risk optimization is also not being undertaken by many of them. This is one of the major research gap which needs to be addressed. In order to benchmark the best healthcare practices during such pandemic; demand and supply management, collaboration between public and private partners, collaboration between the primary and secondary healthcare, employee-and-patient centric resources are required to be facilitated for further functioning of the healthcare systems and address the critical issues. Optimization of risks is also crucial not only for addressing the shortages in healthcare staffs, PPEs, equipment, etc. but also to rather prepare a robust disaster plan while implementing lean practices along with Industry 4.0 technologies for a sustainable healthcare system in place. It is, therefore, essential to make a resilient supply chain to assess decision-making in times of epidemic outbreaks (Dolgui \& Ivanov, 2021; Ivanov, 2020). Several researchers have published articles regarding supply chain disruption modelling (Cui et al., 2016; Hou et al., 2018; Ivanov, 2017; Torabi et al., 2015; Wilson, 2007; Zhang et al., 2015). Moreover, there are several opportunities to improve International Competitiveness (IC) of the healthcare industry from Indian perspective also.

\section{Managerial Implications}

Competitiveness plays an important role in improving the efficiency, productivity of any firm while building a sustainable ecosystem. The emerging economies, like India may reap huge benefit due to ample number of existing opportunities. The findings of the study clearly state the critical need for the modelling approaches in order to mitigate the various risks generated in a healthcare supply chain, particularly during and post-pandemic. The results of the study help the practitioners and healthcare managers to use the various models for facilitating the resources across the supply chain and therefore plan accordingly in future for a resilient and sustainable healthcare supply chain. Moreover, this brings on advantages and opportunities for promoting medical tourism and use of emerging technologies for building various dimensions of competitiveness and sustainability (Chauhan et al., 2021; Mishra \& Sharma, 2021; Momaya, 2020).

\section{Conclusion, Limitations and Agenda for Future Research}

This review has identified all the existing modelling approaches related to supply chain disruption modelling, with respect to risk-specific criteria from the literature. The analysis indicates that modelling approaches fulfil a great number of risk-specific requirements, but still a lot of progress needs to be made. Especially, on the main network 
Table 2 Modelling approach to model healthcare supply chain disruption

\begin{tabular}{|c|c|c|c|c|c|c|c|c|}
\hline Author & $\begin{array}{l}\text { Number } \\
\text { of risks }\end{array}$ & $\begin{array}{l}\text { Risk } \\
\text { propa- } \\
\text { gation }\end{array}$ & Duration of risk & $\begin{array}{l}\text { Risk } \\
\text { identifi- } \\
\text { cation }\end{array}$ & $\begin{array}{l}\text { Risk } \\
\text { assess- } \\
\text { ment }\end{array}$ & $\begin{array}{l}\text { Mitiga- } \\
\text { tion of } \\
\text { risk }\end{array}$ & $\begin{array}{l}\text { Risk } \\
\text { optimi- } \\
\text { zation }\end{array}$ & Modeling approaches \\
\hline Brailsford et al. (2004) & 1 & No & ND & Yes & Yes & Yes & No & System Dynamics \\
\hline Liu (2007) & 2 & No & LT & Yes & Yes & No & Yes & Mathematical Programming \\
\hline $\begin{array}{l}\text { Arinaminpathy and Mclean } \\
\text { (2008) }\end{array}$ & 2 & Yes & LT & Yes & Yes & Yes & No & $\begin{array}{l}\text { Mathematical Modelling } \\
\text { (differential equation and } \\
\text { compartmental Modelling) }\end{array}$ \\
\hline Chick et al. (2008) & 1 & No & $\mathrm{N}$ & No & No & No & No & Mathematical Model \\
\hline Delaurentis et al. (2008) & 2 & Yes & LT & Yes & Yes & No & No & Game Theory \\
\hline Lee (2008) & 3 & No & LT & Yes & Yes & No & No & Simulation \\
\hline Lee et al. (2009) & 1 & No & ND & Yes & Yes & No & Yes & Mathematical modelling \\
\hline Kamp et al. (2010) & 2 & Yes & $\mathrm{LT}$ & Yes & No & No & No & SIR mathematical model, \\
\hline Hui (2010) & 1 & No & LT & Yes & Yes & No & Yes & Queuing Theory \\
\hline Mete and Zabinsky (2010) & 3 & No & ST & Yes & Yes & No & No & $\begin{array}{l}\text { Two Stage Stochastic Optimi- } \\
\text { zation }\end{array}$ \\
\hline Adida et al. (2011) & 2 & No & LT & Yes & Yes & No & No & Game Theory \\
\hline Sha and Huang (2012) & 3 & No & ST & Yes & Yes & Yes & No & $\begin{array}{l}\text { Lagrangean Relaxation, } \\
\text { Mathematical Programming } \\
\text { Formulation }\end{array}$ \\
\hline Wang et al. (2012) & 1 & No & ND & Yes & Yes & No & No & Agent-Based Modelling \\
\hline Anagnostou et al. (2013) & 4 & No & ND & Yes & Yes & No & No & $\begin{array}{l}\text { Hybrid Modelling (Discrete } \\
\text { Event Simulation and Agent- } \\
\text { based simulation) }\end{array}$ \\
\hline Mamani et al. (2013) & 1 & Yes & ND & Yes & No & No & No & Game Theory \\
\hline Allen et al. (2014) & 1 & No & ND & Yes & Yes & No & Yes & Discrete Event Simulation \\
\hline Elleuch et al. (2014) & 3 & Yes & ND & Yes & Yes & Yes & No & $\begin{array}{l}\text { Discrete Event Simulation, } \\
\text { AHP }\end{array}$ \\
\hline Jabbarzadeh et al. (2014) & 4 & No & ST & Yes & Yes & No & Yes & Robust Optimization Model \\
\hline Fakhimi et al. (2015) & 1 & No & ND & Yes & Yes & No & No & $\begin{array}{l}\text { Hybrid Modelling (Discrete } \\
\text { Event Simulation and Agent- } \\
\text { based simulation) }\end{array}$ \\
\hline $\begin{array}{l}\text { Shishebori and Yousefi } \\
\text { Babadi (2015) }\end{array}$ & 2 & No & ND & Yes & Yes & No & Yes & $\begin{array}{l}\text { Mixed-integer linear program- } \\
\text { ming model }\end{array}$ \\
\hline $\begin{array}{l}\text { Hasani and Khosrojerdi } \\
\text { (2016) }\end{array}$ & 2 & No & ST & No & No & Yes & No & $\begin{array}{l}\text { Mixed-integer linear program- } \\
\text { ming model }\end{array}$ \\
\hline Liu and Zhang (2016) & 2 & Yes & LT & Yes & Yes & Yes & No & FPEA Model \\
\hline Lücker and Seifert (2017) & 1 & No & LT \& ST & Yes & Yes & Yes & Yes & Mathematical model \\
\hline Fahimnia et al. (2017) & 5 & No & ST & Yes & Yes & No & No & $\begin{array}{l}\text { Stochastic bi-objective Supply } \\
\text { Chain model, Hybrid solu- } \\
\text { tion approach, combining } \\
\text { e- constraint and Lagrangean } \\
\text { relaxation method }\end{array}$ \\
\hline Parvin et al. (2018) & 3 & No & ST & Yes & Yes & Yes & Yes & System Dynamics \\
\hline Shamsi et al. (2018) & 2 & Yes & LT & Yes & Yes & No & Yes & $\begin{array}{l}\text { Hybrid Modelling (Stackelberg } \\
\text { Game Model and Nonlinear } \\
\text { Programming Model) }\end{array}$ \\
\hline Aldrighetti et al. (2019) & 1 & Yes & LT \& ST & Yes & Yes & Yes & No & Simulation \\
\hline Timajchi et al. (2019) & 2 & No & ND & Yes & Yes & No & Yes & $\begin{array}{l}\text { Mixed-integer linear program- } \\
\text { ming model }\end{array}$ \\
\hline Haghjoo et al. (2020) & 2 & No & ST & Yes & Yes & No & Yes & $\begin{array}{l}\text { Meta heuristic model, Monte- } \\
\text { Carlo simulation }\end{array}$ \\
\hline Paul et al. (2020) & 1 & No & ND & Yes & No & Yes & No & Bayesian Belief Network \\
\hline Govindan et al. (2020) & 1 & Yes & LT & Yes & Yes & Yes & No & Fuzzy Modelling \\
\hline
\end{tabular}


Table 2 (continued)

\begin{tabular}{|c|c|c|c|c|c|c|c|c|}
\hline Author & $\begin{array}{l}\text { Number } \\
\text { of risks }\end{array}$ & $\begin{array}{l}\text { Risk } \\
\text { propa- } \\
\text { gation }\end{array}$ & Duration of risk & $\begin{array}{l}\text { Risk } \\
\text { identifi- } \\
\text { cation }\end{array}$ & $\begin{array}{l}\text { Risk } \\
\text { assess- } \\
\text { ment }\end{array}$ & $\begin{array}{l}\text { Mitiga- } \\
\text { tion of } \\
\text { risk }\end{array}$ & $\begin{array}{l}\text { Risk } \\
\text { optimi- } \\
\text { zation }\end{array}$ & Modeling approaches \\
\hline Hamdan and Diabat (2020) & 4 & No & ST & Yes & Yes & Yes & Yes & $\begin{array}{l}\text { Two Stage Stochastic Optimi- } \\
\text { zation Model, Lagrangean } \\
\text { Relaxation }\end{array}$ \\
\hline
\end{tabular}

$S T$ short term, $L T$ long term, $N D$ not defined

level, risk characteristics, namely risk propagation, risk mitigation should be given more emphasis by future research efforts. In addition to this, data basis of all the approaches could be given a more central role to increase the validity of models.

This systematic literature review used the keywords based on several number of trials so that it can cover most of the articles. Although there can be a possibility that some modelling approaches has not been covered because specified modelling approach was not the search criteria, instead of this a general keyword for modelling has been used. Secondly, the articles from business and management domain are only considered. There is a possibility that some articles exist in other subject areas. Future research studies can develop some methodology to deal with these limitations.

Most of the studies has been done for short-term disruption. In future, suitable modelling techniques for mediumterm disruption and long-term disruption in healthcare supply chain are required to be explored. Furthermore, the use of Multi-Criteria Decision-Making, Stochastic Programming, Input-Output modelling approach may be used to deal with supply chain disrutpion in healthcare sector. In addition to that, prospective models should put more emphasis on resilience and risk control in HSCM. It is, therefore, expected that the research field to grow further, expand, and play a more decisive role for academics and practitioners from competitiveness point of view.

\section{Key Questions Reflecting Applicability in Real Life}

1. What are the critical barriers/challenges in healthcare supply chain for achieving resiliency and sustainability?

2. How to address the ethical issues in a healthcare industry?

3. What are the key factors that drive digital health business post-pandemic in improving the competitiveness of healthcare industry?

4. What dimensions facilitate patient's safety and mental health post-and-beyond pandemic?
5. What are the major challenges for the implementation of lean six sigma in Indian hospitals?

Acknowledgements We would like to give our sincere gratitude to Editor-in-Chief, Guest editors, and anonymous reviewers for guiding us to improve the manuscript. We would also like to thank Indian Institute of Management, Sambalpur and Guildhall School of Business and Law, London Metropolitan University for providing the required infrastructure to complete this manuscript.

Author contributions AS: conceptualization, methodology, writingoriginal draft preparation, and validation. RP: conceptualization, supervision, visualization, writing, reviewing and editing, and validation.

Funding The authors declare that there was no funding agencies that provided research grant and support for this research. The authors declare that there are no financial or non-financial interests that are directly or indirectly related to the work submitted for publication.

Data availability Available on request.

Code availability Not applicable.

\section{Declarations}

Conflict of interest The authors declare there is no conflict of interest.

Data transparency All authors ensure that all data as well as software application and support the published claims and comply with field standards.

\section{References}

Adida, E., DeLaurentis, P. C. C., \& Lawley, M. A. (2011). Hospital stockpiling for disaster planning. IIE Transactions, 43(5), 348362. https://doi.org/10.1080/0740817X.2010.540639

Aharon, B. T., Laurent, E. G., \& Arkadi, N. (2009). Robust optimization. Princeton University Press.

Aldrighetti, R., Zennaro, I., Finco, S., \& Battini, D. (2019). Healthcare supply chain simulation with disruption considerations: A case study from Northern Italy. Global Journal of Flexible Systems Management, 20(1), 81-102. https://doi.org/10.1007/ S40171-019-00223-8

Allen, R. W., Taaffe, K. M., \& Ritchie, G. (2014).Surgery Reschedulling using discrete event simulation: A case study. In: Proceedings of the Winter Simulation Conference IEEE 2014, pp. 1365-1376. 
Anagnostou, A., Nouman, A., \& Taylor, S. J. (2013). Distributed hybrid agent-based discrete event emergency medical services simulation. In: Winter Simulations Conference (WSC) IEEE 2013, 1625-1636. https://doi.org/10.1109/WSC.2013.6721545.

Arinaminpathy, N., \& Mclean, A. R. (2008). Antiviral treatment for the control of pandemic influenza: Some logistical constraints. $J R$ Society Interface, 5, 545-553. https://doi.org/10.1098/rsif.2007. 1152

Azghandi, R., Griffin, J., \& Jalali, M. S. (2018). Minimization of drug shortages in pharmaceutical supply chains: A simulation-based analysis of drug recall patterns and inventory policies. Complexity. https://doi.org/10.1155/2018/6348413

Bag, S., Gupta, S., \& Telukdarie, A. (2018). Importance of innovation and flexibility in configuring supply network sustainability. Benchmarking, 25(9), 3951-3985. https://doi.org/10.1108/ BIJ-06-2017-0132

Battini, D., Faccio, M., Persona, A., \& Sgarbossa, F. (2013). Modelling the growing process of integrated healthcare supply networks. International Journal of System Dynamics Applications, 2(1), 1-13. https://doi.org/10.4018/ijsda.2013010101

Battini, D., Persona, A., \& Sgarbossa, F. (2014). A sustainable EOQ model: Theoretical formulation and applications. International Journal of Production Economics, 149, 145-153. https://doi.org/ 10.1016/j.ijpe.2013.06.026

Bourlakis, M., Clear, F., Patten, L., Bourlakis, M., \& Patten, L. (2011). Understanding the UK Hospital Supply Chain in an Era of Patient Choice. Journal of Marketing Management, 27(3-4), 401-423. https://doi.org/10.1080/0267257X.2011.547084

Brailsford, S. C., Lattimer, V. A., Tarnaras, P., \& Turnbull, J. C. (2004). Emergency and on-demand health care: Modelling a large complex system. Journal of the Operational Research Society, 55(1), 34-42. https://doi.org/10.1057/palgrave.jors.2601667

Bugert, N., \& Lasch, R. (2018). Supply chain disruption models: A critical review. Logistics Research. https://doi.org/10.23773/2018_5

Burgess, N., \& Radnor, Z. (2013). Evaluating Lean in healthcare. International Journal of Health Care Quality Assurance, 26(3), 220-235. https://doi.org/10.1108/09526861311311418

Chauhan, C., Akram, M. U., \& Gaur, D. (2021). Technologydriven responsiveness in times of COVID-19: A fuzzy Delphi and fuzzy AHP-based approach. International Journal of Global Business and Competitiveness. https://doi.org/10.1007/ s42943-021-00036-6

Chick, S. E., Mamani, H., \& Simchi-Levi, D. (2008). Supply chain coordination and influenza vaccination. Operationas Research, 56(6), 1493-1506. https://doi.org/10.1287/OPRE.1080.0527

Chopra, S., \& Sodhi, M. S. (2004). Managing risk to avoid supplychain breakdown. MIT Soan Management Review, 46 (1), 53-61

Cui, J., Zhao, M., Li, X., Parsafard, M., \& An, S. (2016). Reliable design of an integrated supply chain with expedited shipments under disruption risks. Transportation Research Part E: Logistics and Transportation Review, 95, 143-163. https://doi.org/10. 1016/j.tre.2016.09.009

de Vries, J., \& Huijsman, R. (2011). Supply chain management in health services: An overview. Supply Chain Management: An International Journal, 16(3), 159-165. https://doi.org/10.1108/ 13598541111127146

Delaurentis, P.-C., Adida, E., \& Lawley, M. (2008). A game theoretical approach for hospital stockpile in preparation for pandemics. In: Proceedings of the 2008 Industrial engineering research conference, 101, p.1

DeSalvo, K., Parekh, A., William Hoagland, G., Dilley, A., Kaiman, S., Hines, M., \& Levi, J. (2019). Developing a financing system to support public health infrastructure. American Journal of Public Health, 109(10), 1358-1361. https://doi.org/10.2105/AJPH.2019. 305214
Deshmukh, S. G., \& Haleem, A. (2020). Framework for manufacturing in post-COVID-19 world order: An Indian Perspective. International Journal of Global Business and Competitiveness. https:// doi.org/10.1007/s42943-020-00009-1

Diabat, A., Jabbarzadeh, A., \& Khosrojerdi, A. (2019). A perishable product supply chain network design problem with reliability and disruption considerations. International Journal of Production Economics, 212, 125-138. https://doi.org/10.1016/j.ijpe.2018. 09.018

Dolgui, A., \& Ivanov, D. (2021). Ripple effect and supply chain disruption management: New trends and research directions. International Journal of Production Research, 59(1), 102-109. https:// doi.org/10.1080/00207543.2021.1840148

Dubey, R., Gunasekaran, A., Childe, S. J., Fosso Wamba, S., Roubaud, D., \& Foropon, C. (2019). Empirical investigation of data analytics capability and organizational flexibility as complements to supply chain resilience. International Journal of Production Research. https://doi.org/10.1080/00207543.2019.1582820

Elleuch, H., Hachicha, W., \& Chabchoub, H. (2014). A combined approach for supply chain risk management: Description and application to a real hospital pharmaceutical case study. Journal of Risk Research, 17(5), 641-663. https://doi.org/10.1080/13669 877.2013.815653

Fahimnia, B., Jabbarzadeh, A., Ghavamifar, A., \& Bell, M. (2017). Supply chain design for efficient and effective blood supply in disasters. International Journal of Production Economics, 183, 700-709. https://doi.org/10.1016/j.ijpe.2015.11.007

Fahimnia, B., Tang, C. S., Davarzani, H., \& Sarkis, J. (2015). Quantitative models for managing supply chain risks: A review. European Journal of Operational Research, 247(1), 1-15. https://doi.org/10. 1016/j.ejor.2015.04.034

Fakhimi, M., Anagnostou, A., Stergioulas, L., \& Taylor, S. J. E. (2015). A hybrid agent-based and Discrete Event Simulation approach for sustainable strategic planning and simulation analytics. Proceedings-Winter Simulation Conference, 2015, 1573-1584. https://doi. org/10.1109/WSC.2014.7020009

Francis, J. R. (2020). COVID-19: Implications for Supply Chain Management. Frontiers of Health Services Management, 37(1), 33-38. https://doi.org/10.1097/HAP.0000000000000092

Govindan, K., Mina, H., \& Alavi, B. (2020). A decision support system for demand management in healthcare supply chains considering the epidemic outbreaks: A case study of coronavirus disease 2019 (COVID-19). Transportation Research Part E: Logistics and Transportation Review, 138, 101967. https://doi.org/10.1016/j.tre. 2020.101967

Green, L. V, \& Nguyen, V. (2006). Strategies for cutting hospital beds: the impact on patient service. Health Services Research, 36(2), 421-442. http://www.ncbi.nlm.nih.gov/pubmed/11409821. Retrieved December 29, 2021

Gupta, N., \& Soni, G. (2021). A decision-making framework for sustainable supply chain finance in post-COVID era. International Journal of Global Business and Competitiveness. https://doi.org/ 10.1007/s42943-021-00028-6

Haghjoo, N., Tavakkoli-Moghaddam, R., Shahmoradi-Moghadam, H., \& Rahimi, Y. (2020). Reliable blood supply chain network design with facility disruption: A real-world application. Engineering Applications of Artificial Intelligence. https://doi.org/10.1016/j. engappai.2020.103493

Hamdan, B., \& Diabat, A. (2020). Robust design of blood supply chains under risk of disruptions using Lagrangian relaxation. Transportation Research Part E: Logistics and Transportation Review, 134, 101764. https://doi.org/10.1016/j.tre.2019.08.005

Hasani, A., \& Khosrojerdi, A. (2016). Robust global supply chain network design under disruption and uncertainty considering resilience strategies: A parallel memetic algorithm for a real-life case 
study. Transportation Research Part E: Logistics and Transportation Review, 87, 20-52. https://doi.org/10.1016/j.tre.2015.12.009

Hou, Y., Wang, X., Wu, Y. J., \& He, P. (2018). How does the trust affect the topology of supply chain network and its resilience? An agentbased approach. Transportation Research Part E: Logistics and Transportation Review, 116, 229-241. https://doi.org/10.1016/j. tre.2018.07.001

Hovav, S., \& Tsadikovich, D. (2015). A network flow model for inventory management and distribution of influenza vaccines through a healthcare supply chain. Operations Research for Health Care, 5, 49-62. https://doi.org/10.1016/J.ORHC.2015.05.003

Hui, Q. (2010). Optimal control of bio-attack induced infectious disease dynamics: The case of anthrax. International Conference on Automation Science and Engineering, IEEE 2010, 911-916. /https://doi.org/10.1109/COASE.2010.5584620.

Ivanov, D. (2017). Simulation-based single vs. dual sourcing analysis in the Supply Chain with consideration of capacity disruptions, big data and demand patterns. International Journal of Integrated Supply Management, 11(1), 24-43. https://doi.org/10.1504/IJISM. 2017.083005

Ivanov, D. (2020). Predicting the impacts of epidemic outbreaks on global supply chains: A simulation-based analysis on the coronavirus outbreak (COVID-19/SARS-CoV-2) case. Transportation Research Part E: Logistics and Transportation Review, 136, 101922. https://doi.org/10.1016/j.tre.2020.101922

Ivanov, D., Dolgui, A., Sokolov, B., \& Ivanova, M. (2017). Literature review on disruption recovery in the supply chain. International Journal of Production Research, 55(20), 6158-6174. https://doi. org/10.1080/00207543.2017.1330572

Jabbarzadeh, A., Fahimnia, B., \& Seuring, S. (2014). Dynamic supply chain network design for the supply of blood in disasters: A robust model with real world application. Transportation Research Part $e$ : Logistics and Transportation Review, 70(1), 225-244. https:// doi.org/10.1016/j.tre.2014.06.003

Kamp, C., Heiden, M., Henseler, O., \& Seitz, R. (2010). Management of blood supplies during an influenza pandemic. Transfusion, 50(1), 231-239. https://doi.org/10.1111/j.1537-2995.2009. 02498.x

Kitsiou, S., Matopoulos, A., Manthou, V., \& Vlachopoulou, M. (2007). Evaluation of integration technology approaches in the healthcare supply chain. International Journal of Value Chain Management, 1(4), 325-343. https://doi.org/10.1504/IJVCM.2007.015091

Kumar, P., Bera, S., Dutta, T., \& Chakraborty, S. (2018). Auxiliary flexibility in healthcare delivery system: An integrative framework and implications. Global Journal of Flexible Systems Management, 19(2), 173-186. https://doi.org/10.1007/s40171-018-0183-y

Lee, Y. M. (2008). Analyzing dispensing plan for emergency medical supplies in the event of bioterrorism. In: 2008 Winter simulation conference, pp. 2600-2608.

Lee, E. K., Smalley, H. K., Zhang, Y., Pietz, F., \& Benecke, B. (2009). Facility location and multi-modality mass dispensing strategies and emergency response for biodefence and infectious disease outbreaks. International Journal of Risk Assessment and Management, 12(2-4), 311-351. https://doi.org/10.1504/ijram.2009. 025925

Leite, H., Lindsay, C., \& Kumar, M. (2020). COVID-19 outbreak: Implications on healthcare operations. TQM Journal, 33(1), $247-$ 256. https://doi.org/10.1108/TQM-05-2020-0111/FULL/PDF

Leung, K., Wu, J. T., Liu, D., \& Leung, G. M. (2020). First-wave COVID-19 transmissibility and severity in China outside Hubei after control measures, and second-wave scenario planning: A modelling impact assessment. Lancet, 395(10233), 1382-1393. https://doi.org/10.1016/S0140-6736(20)30746-7

Liu, Y. (2007). Mathematical models of vaccine inventory design for a breakout of epidemic disease. PAMM: Proceedings in Applied
Mathematics and Mechanics, 7(1), 2150013-2150014. https:// doi.org/10.1002/pamm.200700367

Liu, M., \& Zhang, D. (2016). A dynamic logistics model for medical resources allocation in an epidemic control with demand forecast updating. Journal of the Operational Research Society, 67(6), 841-852. https://doi.org/10.1057/jors.2015.105

Lücker, F., \& Seifert, R. W. (2017). Building up resilience in a pharmaceutical supply chain through inventory, dual sourcing and agility capacity. Omega, 73, 114-124. https://doi.org/10.1016/j. omega.2017.01.001

Mamani, H., Chick, S. E., \& Simchi-Levi, D. (2013). A game-theoretic model of international influenza vaccination coordination. Management Science, 59(7), 1650-1670. https://doi.org/ 10.1287/MNSC. 1120.1661

Managing the impact of COVID-19 on India's supply chains-Now, Next and Beyond (2020). Retrieved July 2020 from https:// assets.ey.com/content/dam/ey-sites/ey-com/en_in/topics/gover nment-and-public-sector/2020/09/managing-the-impact-ofcovid-19-on-india-supply-chains.pdf

Mathew, J., John, J., \& Kumar, S. (2013). New trends in healthcare supply chain. In: annals of POMS conference proceedings, pp. $1-10$

McManus, M. L., Long, M. C., Cooper, A., \& Litvak, E. (2004). Queuing theory accurately models the need for critical care resources. The Journal of the American Society of Anesthesiologists, 100(5), 1271-1276.

Mete, H. O., \& Zabinsky, Z. B. (2010). Stochastic optimization of medical supply location and distribution in disaster management. International Journal of Production Economics, 126(1), 76-84. https://doi.org/10.1016/j.ijpe.2009.10.004

Mishra, V., \& Sharma, M. G. (2021). Framework for promotion of medical tourism: A case of India. International Journal of Global Business and Competitiveness. https://doi.org/10.1007/ s42943-021-00027-7

Momaya, K. S. (2020). Return from COVID-19: Thinking differently about export competitiveness and sustainaBILITY. International Journal of Global Business and Competitiveness, 15, 1-9. https://doi.org/10.1007/s42943-020-00012-6

Neve, B. V., \& Schmidt, C. P. (2021). Point-of-use hospital inventory management with inaccurate usage capture. Health Care Management Science. https://doi.org/10.1007/S10729-021-09573-1

Parvin, H., Beygi, S., Helm, J. E., Larson, P. S., \& Van Oyen, M. P. (2018). Distribution of medication considering information, transshipment, and clustering: Malaria in Malawi. Production and Operations Management, 27(4), 774-797. https://doi.org/10.1111/ poms. 12826

Paul, S., Kabir, G., Ali, S. M., \& Zhang, G. (2020). Examining transportation disruption risk in supply chains: A case study from Bangladeshi pharmaceutical industry. Research in Transportation Business \& Management, 37, 100485. https://doi.org/10.1016/J. RTBM.2020.100485

Peng, P., Snyder, L. V., Lim, A., \& Liu, Z. (2011). Reliable logistics networks design with facility disruptions. Transportation Research Part B: Methodological, 45(8), 1190-1211. https:// doi.org/10.1016/j.trb.2011.05.022

Pishvaee, M. S., Rabbani, M., \& Torabi, S. A. (2011). A robust optimization approach to closed-loop supply chain network design under uncertainty. Applied Mathematical Modelling, 35(2), 637-649. https://doi.org/10.1016/j.apm.2010.07.013

Qazi, A., Quigley, J., \& Dickson, A. (2015). Supply Chain Risk management: Systematic literature review and a conceptual framework for capturing interdependencies between risks. In: IEOM - 5th International Conference on Industrial Engineering and Operations Management, Proceeding, 1-13. https://doi.org/ 10.1109/IEOM.2015.7093701. 
Rivard-Royer, H., Landry, S., \& Beaulieu, M. (2002). Hybrid stockless: A case study. Lessons for health-care supply chain integration. International Journal of Operations and Production Management, 22(4), 412-424. https://doi.org/10.1108/01443 570210420412

Salamon, T. (2011). Design of agent-based models. Eva \& Tomas Bruckner Publishing.

Saviano, M., Parida, R., Caputo, F., \& Datta, S. K. (2014). Health care as a worldwide concern. Insights on the Italian and Indian health care systems and PPPs from a VSA perspective. EuroMed Journal of Business, 9(2), 198-220. https://doi.org/10.1108/ EMJB-10-2013-0050

Sha, Y., \& Huang, J. (2012). The multi-period location-allocation problem of engineering emergency blood supply systems. Systems Engineering Procedia, 5, 21-28. https://doi.org/10.1016/j. sepro.2012.04.004

Shamsi, G., \& Ali TorabiShakouri, S. G. H. (2018). An option contract for vaccine procurement using the SIR epidemic model. European Journal of Operational Research, 267(3), 1122-1140. https://doi.org/10.1016/j.ejor.2017.12.013

Shishebori, D., \& Yousefi Babadi, A. (2015). Robust and reliable medical services network design under uncertain environment and system disruptions. Transportation Research Part e: Logistics and Transportation Review, 77, 268-288. https://doi.org/10. 1016/j.tre.2015.02.014

Stecke, K. E., \& Kumar, S. (2009). Sources of supply chain disruptions, factors that breed vulnerability, and mitigating strategies. Journal of Marketing Channels, 16(3), 193-226. https://doi.org/ 10.1080/10466690902932551

Sushil. (2017). Does flexibility mitigate or enhance risk? Global Journal of Flexible Systems Management, 18(3), 169-171. https://doi.org/10.1007/s40171-017-0156-6

System, N. A. of E. (US) and I. of M. (US) C. on E. and the H. C., Reid, P. P., Compton, W. D., Grossman, J. H., \& Fanjiang, G. (2005). Supply-chain management and health care delivery: Pursuing a system-level understanding.

Tako, A. A., \& Robinson, S. (2012). The application of discrete event simulation and system dynamics in the logistics and supply chain context. Decision Support Systems, 52(4), 802-815. https://doi.org/10.1016/j.dss.2011.11.015

Tang, C. S. (2006). Perspectives in supply chain risk management. International Journal of Production Economics, 103(2), 451488. https://doi.org/10.1016/j.ijpe.2005.12.006

Taylor, S. J. E. (2014). Introducing agent-based modeling and simulation. Agent-Based Modeling and Simulation. https://doi.org/ 10.1057/9781137453648_1

Timajchi, A., Mirzapour Al-e-Hashem, S. M. J., \& Rekik, Y. (2019). Inventory routing problem for hazardous and deteriorating items in the presence of accident risk with transshipment option. International Journal of Production Economics, 209, 302-315. https://doi.org/10.1016/j.ijpe.2018.01.018

Torabi, S. A., Baghersad, M., \& Mansouri, S. A. (2015). Resilient supplier selection and order allocation under operational and disruption risks. Transportation Research Part e: Logistics and Transportation Review, 79, 22-48. https://doi.org/10.1016/j.tre. 2015.03.005

Wagner, S. M., \& Bode, C. (2006). An empirical investigation into supply chain vulnerability. Journal of Purchasing and Supply Management, 12(6 SPEC. ISS.), 301-312. https://doi.org/10. 1016/j.pursup.2007.01.004

Wang, Y., Luangkesorn, K. L., \& Shuman, L. (2012). Modeling emergency medical response to a mass casualty incident using agent based simulation. Socio-Economic Planning Sciences, 46(4), 281-290. https://doi.org/10.1016/j.seps.2012.07.002

Wieser, P. (2011). From health logistics to health supply chain management. Supply Chain Forum: an International Journal, 12(1), 4-13. https://doi.org/10.1080/16258312.2011.11517249

Wilson, M. C. (2007). The impact of transportation disruptions on supply chain performance. Transportation Research Part E: Logistics and Transportation Review, 43(4), 295-320. https:// doi.org/10.1016/j.tre.2005.09.008

Worthington, D. (2009). Reflections on queue modelling from the last 50 years. Journal of the Operational Research Society. https://doi.org/10.1057/jors.2008.178

Xu, S., Zhang, X., Feng, L., \& Yang, W. (2020). Disruption risks in supply chain management: A literature review based on bibliometric analysis. International Journal of Production Research. https://doi.org/10.1080/00207543.2020.1717011

Zhang, Y., Qi, M., Lin, W. H., \& Miao, L. (2015). A metaheuristic approach to the reliable location routing problem under disruptions. Transportation Research Part E: Logistics and Transportation Review, 83, 90-110. https://doi.org/10.1016/j.tre.2015. 09.001

Zsidisin, G. A., \& Richie, B. (2009). Supply chain risk: A handbook of assessment, management, and performance. Springer.

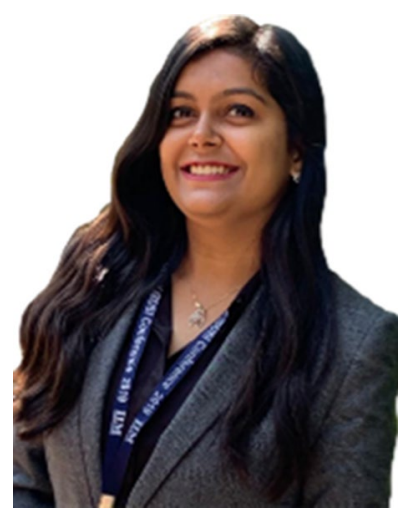

Aarti Singh is currently working as PhD Scholar in the Operations Management domain from Indian Institute of Management, Sambalpur. She has interest to pursue research in Healthcare Operations Management. She has completed Integrated Master's degree from Gautam Buddha University in Biotechnology Stream and published one journal article during her masters.

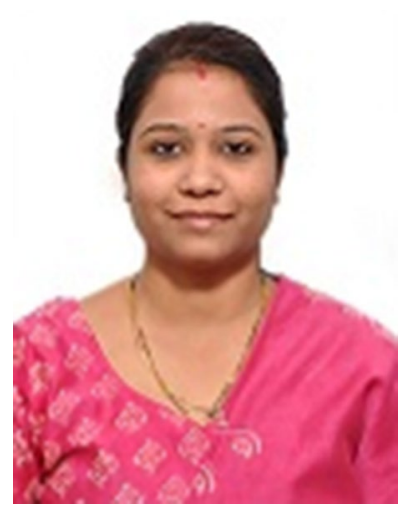

Ratri Parida is working as Associate Professor at IMT Ghaziabad and also a Visiting Research Fellow at Guildhall School of Business and Law, London Metropolitan University, UK. She was associated with many premier institutes in India and was also one of the founding faculty members at Indian Institute of Management (IIM) Sambalpur. She completed PhD from the Department of Industrial and Systems Engineering, Indian Institute of Technology (IIT) Kharagpur. Her research interest focuses specifically on supply chain, Healthcare Operations, Industry 4.0, Sustainability, Ergonomics and Six Sigma. She has published in peer-reviewed journals and participated in International conferences in India and abroad. 